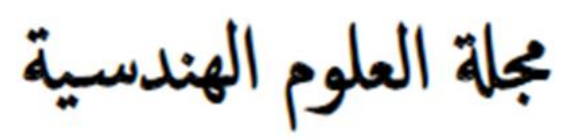

\title{
Foundations, Design, and Dynamic Performance of Wind Turbines: Overview and Challenges in Sudan
}

\author{
Ruba Asim Hamza ${ }^{1, *}$, Amged Osman Abdelatif ${ }^{1}$ \\ 1 Department of Civil Engineering, University of Khartoum, P.O. Box 321, Khartoum, Sudan \\ * Corresponding author: Ruba Asim Hamza (e-mail: rubaeng910@gmail.com).
}

Article history: Received 31 March 2020, Received in revised form 4 November 2020, Accepted 11 November 2020

\begin{abstract}
Sudan is one of the developing countries that suffers from a lack of electricity, where the national electrification rate is estimated at $38.5 \%$. In order to solve this problem, it is possible to use renewable energy sources such as wind energy. Beside many aspects to be considered at the design of wind turbine foundations, more attention should be given to the geotechnical part. There are many types of foundations for wind turbines. The foundation must satisfy two design criteria: 1) It should be safe against bearing failure in soils under design loads and settlements during the life of the structure must not cause structural damage; 2) In addition to static loads, wind turbine foundations loads are extremely eccentrically and the loading is usually highly dynamic. Therefore, the selection of foundation type should consider these two criteria taking into account the nature and magnitude of these loads. This paper presents a review of different types of wind turbine foundations of focusing on on-shore wind turbine foundation types and the dynamic response of wind turbine. The paper also demonstrate experimentally the dynamic response of the wind turbines using wind tunnel facility test on a scaled model.
\end{abstract}

Keywords: wind turbine foundations, dynamic response, and Sudan electrification ratio.

\section{INTRODUCTION}

Wind turbines play a vital role in producing sustainable and clean energy to fulfill the growing energy needs. Energy generated from wind turbines being more sustainable and cost effective. Like many developing countries, Sudan has a shortage of electricity. Hydro-power has the largest share of energy generation. But the potential to expand hydro-power to meet future needs is limited because of climate changes [1]. Sudan doesn't have significant oil or gas production. As a result, they had to resort to importing fossil fuels to meet energy needs. By using the technical feasibility method on the basis of available technologies in 2005, found that eight African countries, including Sudan has large onshore wind energy potential as shown in Fig. 1. Sudan's potential is equivalent to $90 \%$ of its annual energy needs [2].

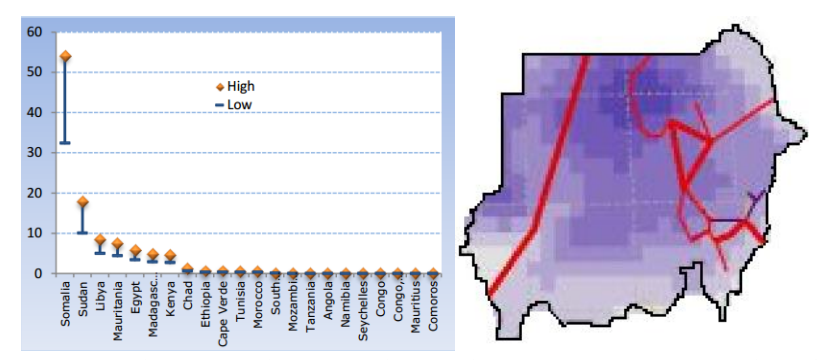

Fig. 1. Onshore Wind Potential in Sudan (Source: [2]-Reproduced from [3])

The Government of Sudan has made a contract with Lahmayer International $\mathrm{GmbH}$ (LI) to conduct a country-wide wind resource assessment program and measurement campaigns. At the end, the first version of wind atlas for Sudan has been published in February 2012. The consultant recommended making further measurement campaigns targeting the three areas in the North of Sudan (Dongola), Red Sea, and Nyala region in South Darfur as shown in Fig. 2. However, up to date, there are no 
previous studies about structural performance of wind turbine considering the different nature of soil in Sudan [1].

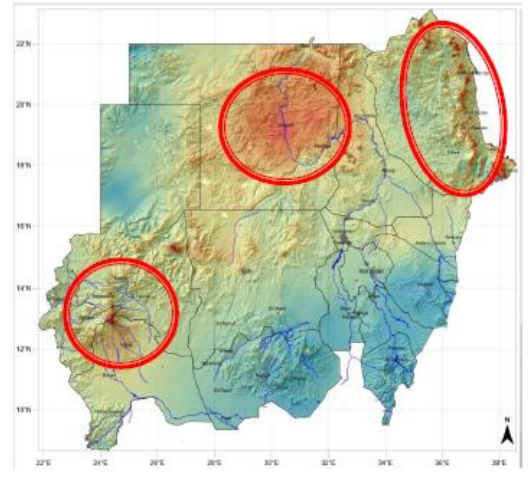

Fig. 2. Wind Turbine in Sudan (Source: [4])

In Sudan, expansive soils prevail over a large area of the country. This area includes most of the nation's population centers, development projects [5]. Looking to the map of potential wind energy in Sudan, Fig. 1, and comparing these areas with the expansive soil map in Sudan shown in Fig. 3, it is clear that some of these areas are of expansive soil. Therefore, when designing the wind turbines foundations, this type of soils should be taken into account and selection the type of wind turbine foundation must have a safety factor against bearing failure in soils under maximum design load and settlements during the life of the structure against structural damage. In addition to static loads, wind turbine foundations are extremely eccentrically loaded and usually highly dynamic.

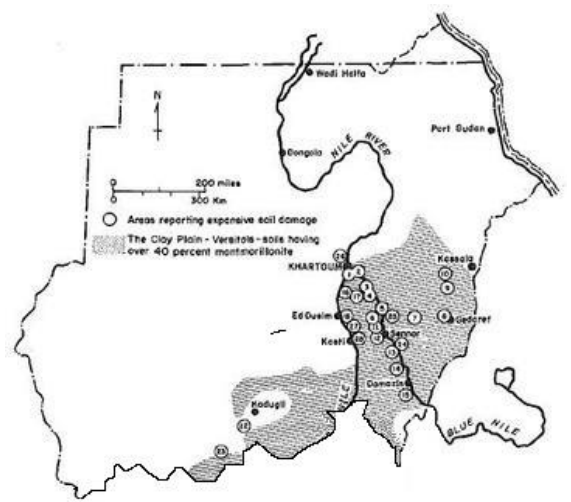

Fig. 3. Expansive Soil in Sudan (Source: Reproduced from [5])

\section{A. Research Problem}

Sudan is one of the developing countries and suffers from a lack of electricity, where the percentage of the population with electricity is estimated at $38.5 \%$ electrification rate. Approximately 24.6 million people lack to access to the electricity in the country. As well as the dispersal of populations and areas of consumption in areas separated by the need to extend long and expensive lines of transmission and distribution of electricity. So there is a problem with the distribution of electricity to the rural areas, in order to solve this problem, it is possible to use clean energy, such as energy generated by wind and solar energy. It is possible to use wind turbines to increase the generation of electricity and hence the electrification rate. However, there are areas with expansive soil so consideration must be given to the choice of type and design of appropriate foundations for wind turbines in un-saturated soils.

The WindAfrica project is a joint collaborative project funded by the UK Engineering and Physical Sciences Research Council EPSRC under the Global Challenges Research Fund (http://community.dur.ac.uk/wind.africa/).

WindAfrica project aims to develop new design guidelines for foundations of wind turbines on expansive soils. As a part from this project, this study aims to bring more light on the dynamic behavior of wind turbine which will help in improving assumptions about tower support condition this in turn will lead to more efficient, safe, and site specific designs. In this study different types of foundations of wind turbine are reviewed. Also the study carried an experimental work on a wind turbine model at the wind tunnel facility at the University of Khartoum to understand the wind-induced forces in the wind turbines.

\section{LITERATURE REVIEW}

\section{A. Types of Wind Turbines Foundations}

\section{A.1 Offshore Wind Turbines Foundations Options}

In addition to the axial load, lateral load and overturning moment, the offshore wind turbine foundation is subjected to up thrust, vibration and large cyclic load due to wave action. The options of offshore wind turbines foundations depend on the depth of water, characteristics of ocean waves, storm surge and the loads from the operation. Some commonly used foundations are shown in Fig. 4 below [6]: 


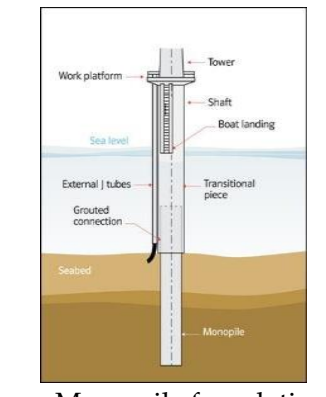

Mono-pile foundation (Source: [7])

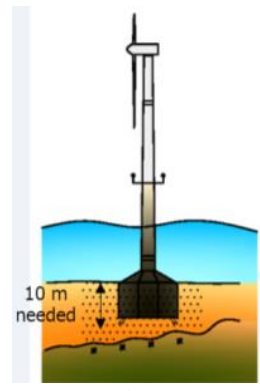

Suction-bucket foundations (Source: [9])

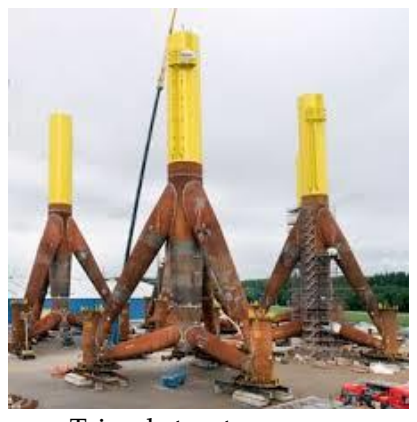

Tripod structure (Source: [11])

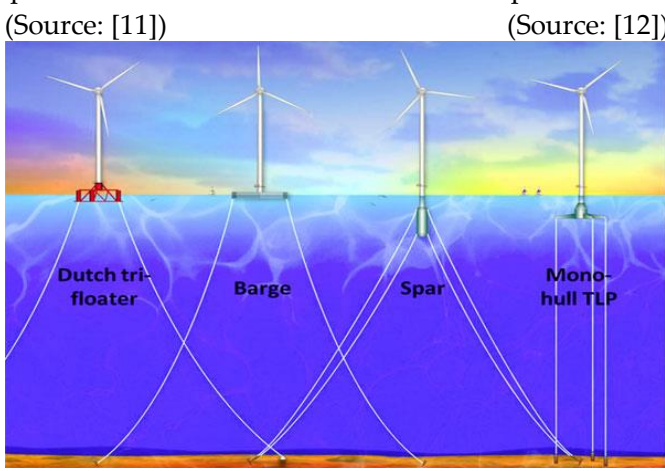

Floating foundations (source: [13])

Fig. 4. Offshore Wind Turbines Foundations

\section{A.2 Onshore Wind Turbines Foundations Options}

They are mostly supported by shallow foundation, deep foundation or combined foundation. The selection of the appropriate foundation depends on the site conditions, available design and analysis procedures and constructability at the site. The shallow foundation is mainly used where the top level soil is able of adequately supporting the superstructure. In cases where the upper soil layer is weak and unable to carry the load, in such cases, a deep foundation is used to transport the load to a deeper stronger soil layer, or bedrock. Deep foundations are used to decrease the excessive differential settlement. Some foundations for onshore wind turbine are shown in Fig. 5 below [6]:

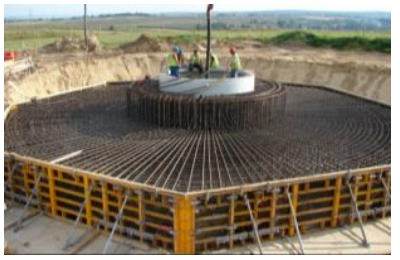

Octagonal gravity foundation (Source: [14])

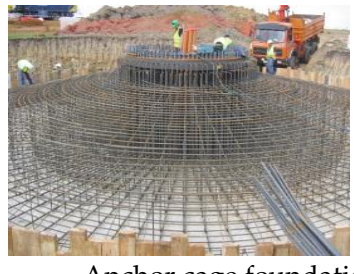

Anchor cage foundation (Source: [15])

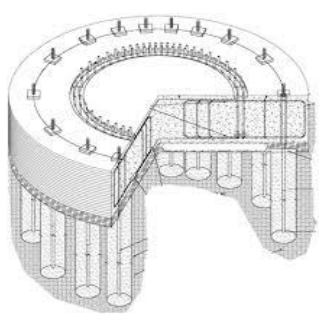

Rock anchor foundation (Source: [16])

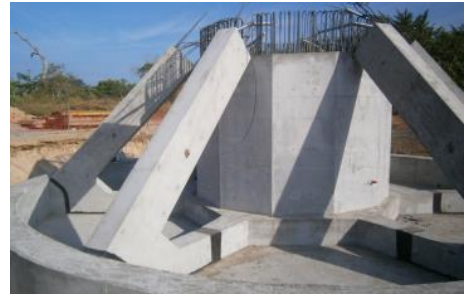

Precast concrete foundation (Source: [17])

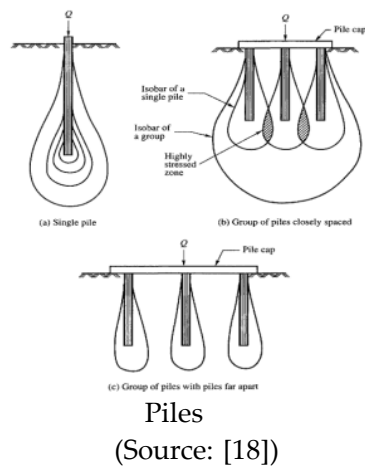

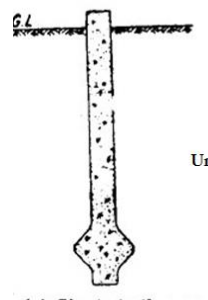

(a) Single-bulb cast in-situ pile
(Source: [18])

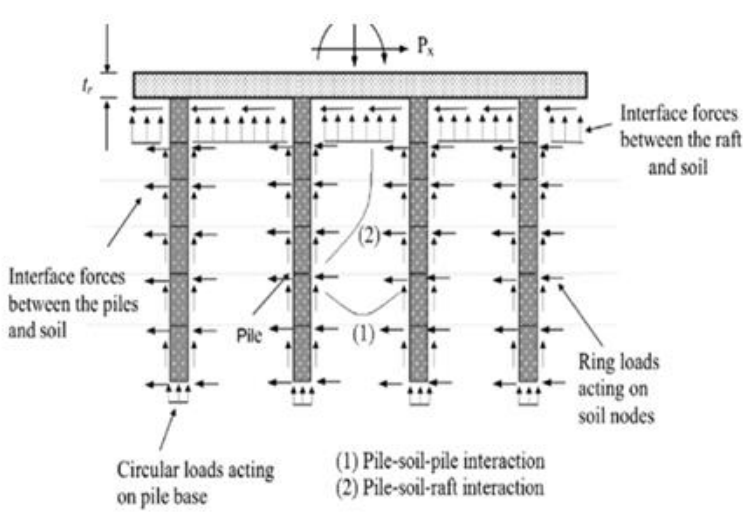

Piled raft foundation (Source: [20])

Fig. 5. Onshore Wind Turbines Foundations

\section{B. Wind Turbine Design}

\section{B.1 Wind Turbine Design Procedure}

Wind turbine design is an intricate procedure. If it is not designed correctly and appropriately, it can result in catastrophic failure and immense 
loss of costs invested. Proper and diligence studies should be carried out during the design of wind turbines. Several codes, standards, and guidelines are available to assist with the design of wind turbines. Some of the most common and applicable include: IEC-61400-1 Wind turbines Design requirements (International Electro-technical Commission- 2005) [21], Guidelines for Design of Wind Turbines (DNV/Risø - 2002) [22]. Unfortunately these guidelines tend to only focus on wind turbines with steel towers. There is little information available on design guidelines related to reinforced concrete towers [23].

\section{B. 2 Turbine Tower Design}

The tower would be one of the main components of the turbine to be designed by civil engineers. According to Van Zyl and Van Zijl (2015), there are two options available to ensure that a wind turbine is dynamically sound. The first option is to avoid the occurrence of resonance altogether so as to ensure that the fundamental natural frequency of the structure differs as far as practically possible from the applied excitation frequency that the structure is likely to be exposed to over its lifespan. The second option is to make use of damping systems to decrease the amplification factor as a result of applied excitation load. The first option is most favorable in industry [24]. The tower should be designed so that the natural frequency is kept out of range of both of rotor rotational frequency and the blade passing frequency by $10 \%$. If this is the case, then there will normally not be any problems as the occurrence of load amplification or resonance is unlikely [22].

\section{B.3 Turbine Tower Loads}

IEC 61400-1 standard provides eight design situations to be taken into account for the design of turbines. Turbine loads have been simplified to include primarily the dead load (self-weight) and wind loads. These loads acting on rotor blades, hub and nacelle are then transferred to the tower are known as turbine loads. The wind load results in a direct pressure along the tower [24] as illustrated in Fig. 6.

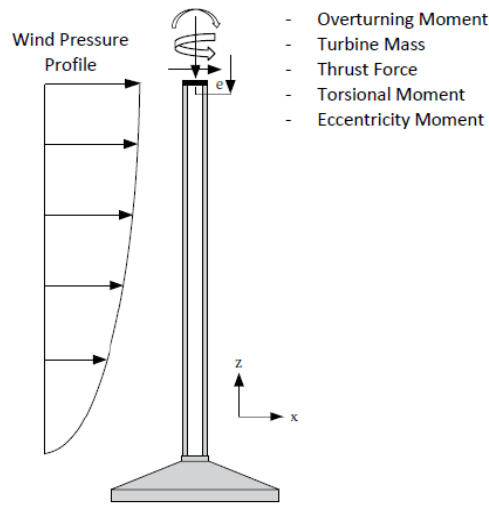

Fig. 6. Typical wind turbine tower loads (source: [25])

\section{Wind-Structure Interaction}

Wind flowing past a wind turbine results in aerodynamic loads. Wind fields acting on the structure are of a stochastic nature meaning that they vary in speed and direction with time. This is a result of turbulent activity in the atmosphere [26]. This turbulent wind field can be seen in Fig. 7. The wind passes through the blades creating lift and drag forces which can be broken up into component vectors that are parallel (acts as a load on the structure itself) and perpendicular (makes the blades to rotate) to the wind direction [27].

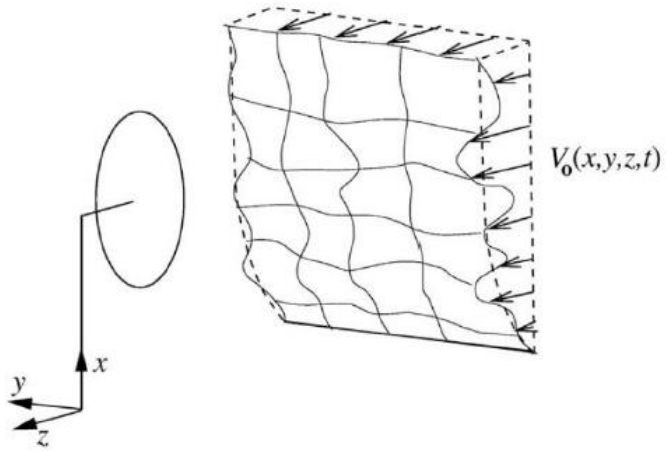

Fig. 7. Illustration of turbulent wind field applied to the turbine (source: [26])

\section{Dynamic Analysis of Wind Turbine Overview}

The dynamic analysis and response of the wind turbine is the focus of this research. The dynamic analysis of a structure has been described by Zingoni (2015) as the response of the structure to a load that varies with time. The response of the structure refers to the displacement, velocity and acceleration of the structure's components, which in turn results in stresses and strains. This response needs to be either eliminated or controlled. The structure may not contain an excitation load applied in the event of free vibration or such load can be applied in case of forced vibration [28]. Dynamic analysis and response of structure are usually interpreted with a single degree of freedom system. This system is 
comprised of a mass, a spring providing stiffness and a damper to dissipate energy as depicted in Fig. 8. The displacement response (X) of the mass is dependent on the excitation frequency $(\Omega)$. This has been well explained by Van Der Tempel and Molenaar (2002) [29].

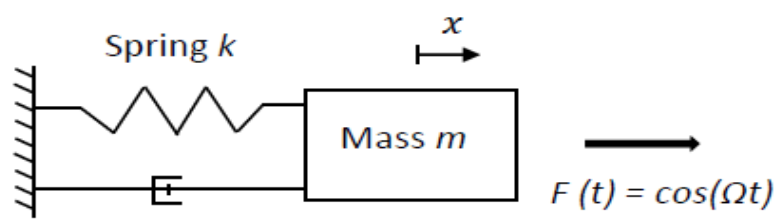

Damper $C$

Fig. 8. Single degree of freedom system (source: [29])

\section{E. Load-deformation Analysis of a Pile in Expansive Soil upon Infiltration}

Piles are one of the popular options to be used as foundation of wind turbines. Piles are widely used as foundations in areas with expansive soil deposits to carry loads safely from superstructure to soil without unacceptable deformations. These foundations are usually designed on the assumption that soil in saturated state. However, the soil surrounding the pile in expansive soil is usually in an unsaturated state. As a result of this reason, the mechanical behavior of the pile is significantly affected by matric suction [30]. So that, the pile load transfer model proposed by Zhang and Zhang (2012) [31] is modified by [30] taking account of the influence of matric suction on the pile-soil interface shear strength for calculating the load-deformation behavior. Fig. 9 illustrates the mechanical behavior of single pile in expansive soil before and after water or rainfall infiltration. Positive friction developed along the length of the pile before infiltration. The superstructure load is carried along the length and at the tip of the pile [as shown in Fig. 9(A)]. As water infiltrates into the active zone [as shown in Fig. 9(B)], three main changes that arise in the soil and pile behavior should be given due consideration for the rational design of pile foundations: (i) In the vertical direction, there is ground heave due to the expansion of soil volume; (ii) In the horizontal direction, the development of lateral swelling pressure occurs due to restricted volume expansion, which should be taken into consideration; (iii) The strength properties of pile-soil interface change due to variations in water content of the surrounding soil [30].

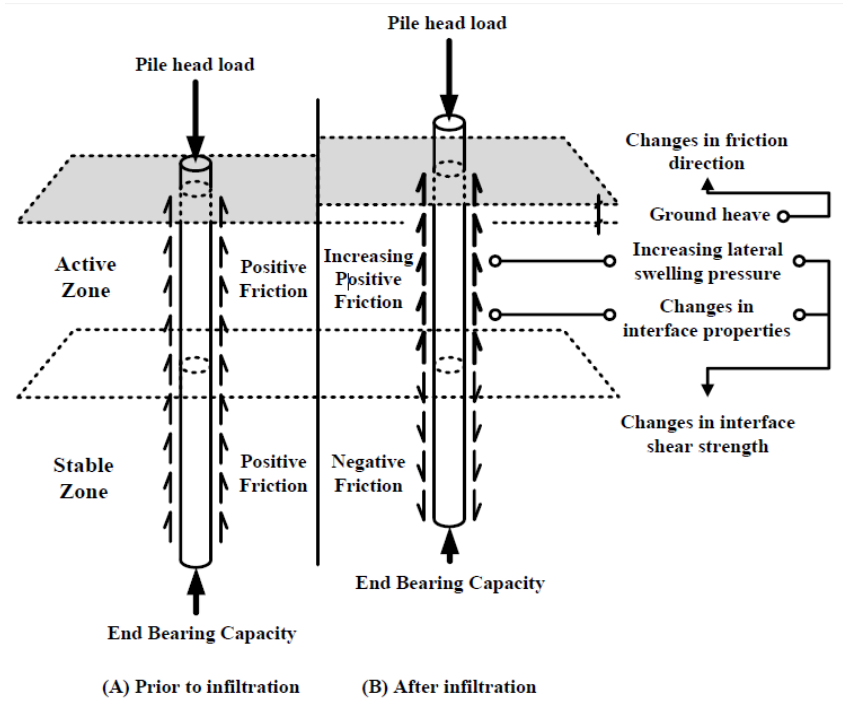

Fig. 9. Mechanical behavior changes of a pile placed in a typical expansive soil before and after infiltration (source: [30])

\section{F. Collapse patterns of wind turbine}

Design loads of wind energy power units on land are mainly dominant by the lateral wind force. For wind forces, many different failure patterns must be discussed for each wind power unit. Structural failure of the tower, foundation, the blades, etc. as well as the fatigue of the parts of the machines are estimated to perform wind energy power units. Wind energy power units should not be overturned and collapsed as shown in Fig. 10 . Also excessive lean of the tower gives low electric power and the possibility of contact of the blades with the tower [32].

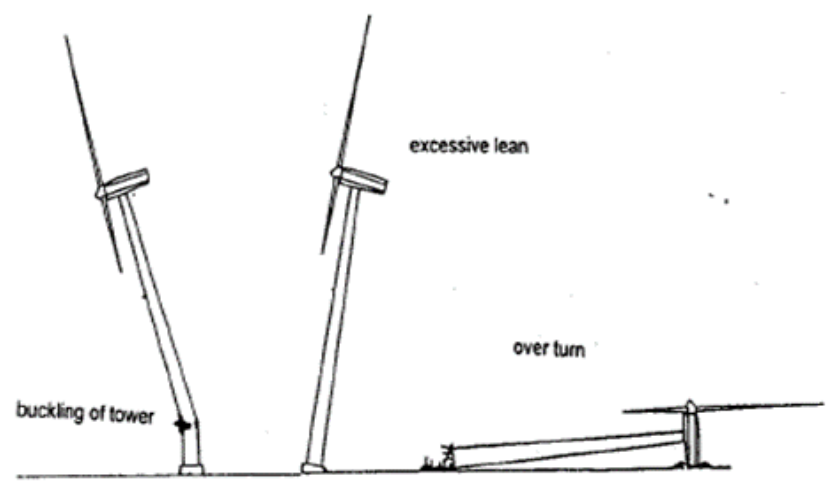

Fig. 10. Collapse patterns of wind energy power units (source: [32])

\section{EXPERIMENTAL WORK}

\section{A. Set-up and procedure for the testing}

This section describes the test procedure and set-up was used for finding out the dynamic response of a wind turbine scaled model. 
Test was conducted in the wind tunnel facility at Khartoum University, in order to investigate the dynamic response of a wind turbine scaled model through show the displacements-time history responses of the top wind turbine.

The lateral loading on the small-scale wind turbine model was produced by a wind tunnel as the flow source. The controller of wind tunnel is shown in Fig. 11.

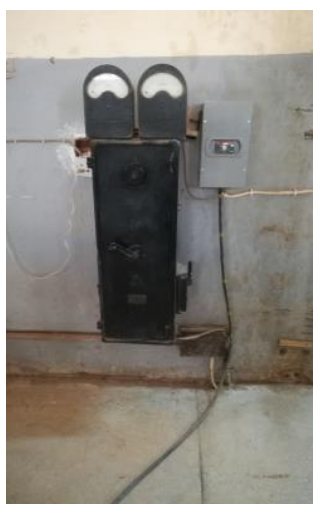

Fig. 11. Wind tunnel controller

The small-scale of wind turbine model was put on seat and fastened with dial gauges device from the base of the model. After that they were placed at one meter away in front of the wind tunnel. "Aerodynamic filter" was placed in the direction of the wind tunnel to obtain a more balanced flow as shown in Fig. 12.

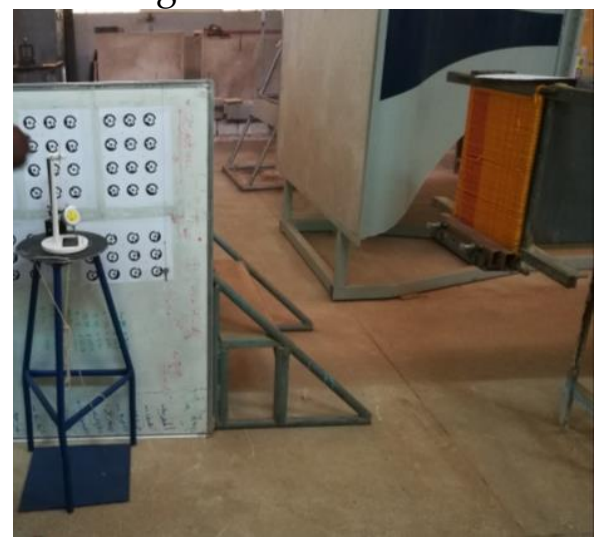

Fig. 12. The wind turbine in front of the wind tunnel

The turbine model was subjected to lateral wind loads with five different wind speeds as shown in Table I. The wind speed of wind tunnel was measured by CFM Anemometer as shown in Fig. 13.

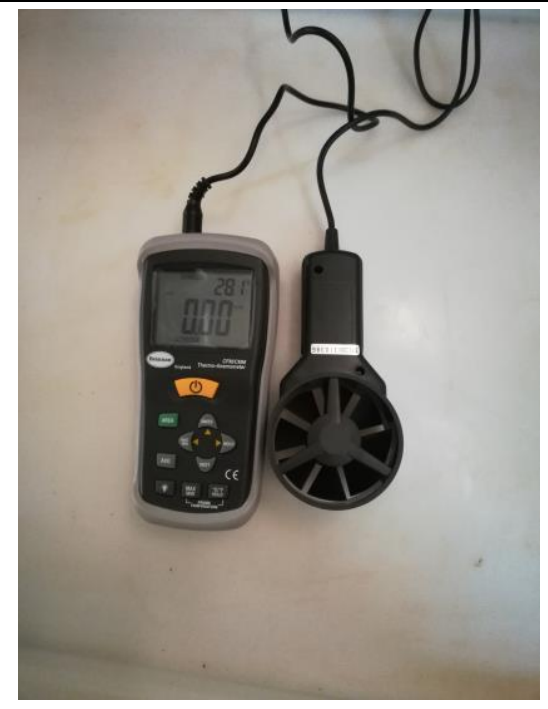

Fig. 13. Anemometer

Table I: Average wind speeds for wind tunnel

\begin{tabular}{lccccc}
\hline Average wind & 1 & 2 & 3 & 4 & 5 \\
\cline { 2 - 6 } speed $(\mathrm{m} / \mathrm{s})$ & 6.68 & 7.23 & 7.83 & 8.39 & 9.08 \\
\hline
\end{tabular}

In this test, a high-resolution camera of 25 frames per second is used to record the performance of model under lateral wind load as shown in Fig. 14 and photogrammetric method was conducted for precise measurements to calculate the displacement of the wind turbine at the top of the tower in wind direction $(X)$ and vertical direction $(\mathrm{Y})$ for one second by using PhotoModeler software.

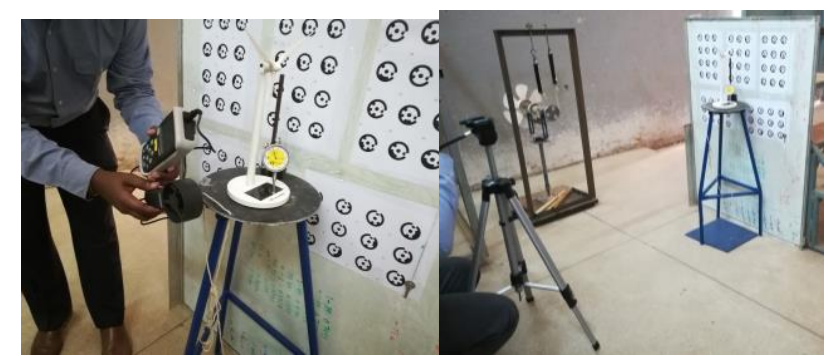

Fig. 14. High-resolution camera to record the performance of model under lateral wind load

\section{RESULTS AND DISCUSSION}

In this section, the results of the lateral displacement of the wind turbine under wind load for a time period of 1.0 second are presented below. Thanks to photogrammetry making such measurements possible. Such a behavior has to be fully considered in the design as discussed in Section 2.4.

The dynamic response of a wind turbine scaled 
model through show the displacements-time history responses of the top wind turbine under wind load in wind direction $(X)$ and vertical direction ( $\mathrm{Y}$ ) is described in Fig. 15 and Fig. 16 respectively for speed (1) speed (5). Therefore, this kind of the dynamic effect of wind turbine should be taken into account to more efficient, safe designs of foundation. More importantly, to observe the displacement results show the effect of blade passing to distort the displacement wave.

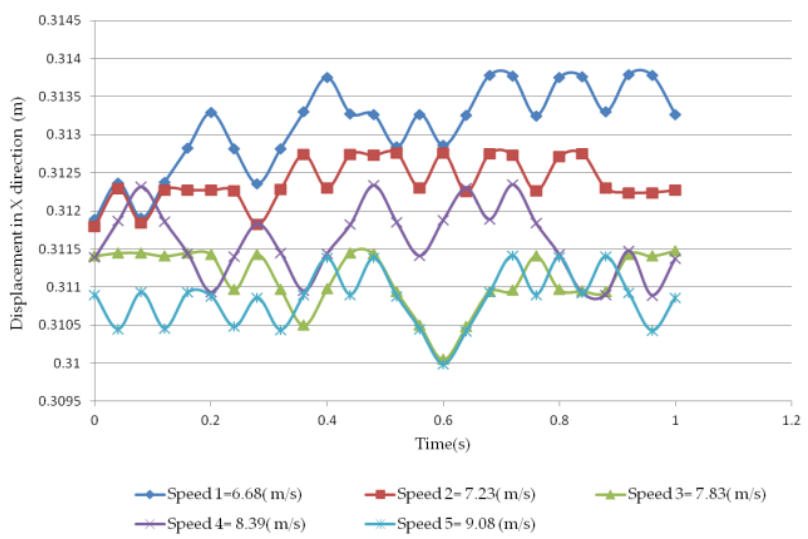

Fig. 15. Displacement response under wind load in wind direction

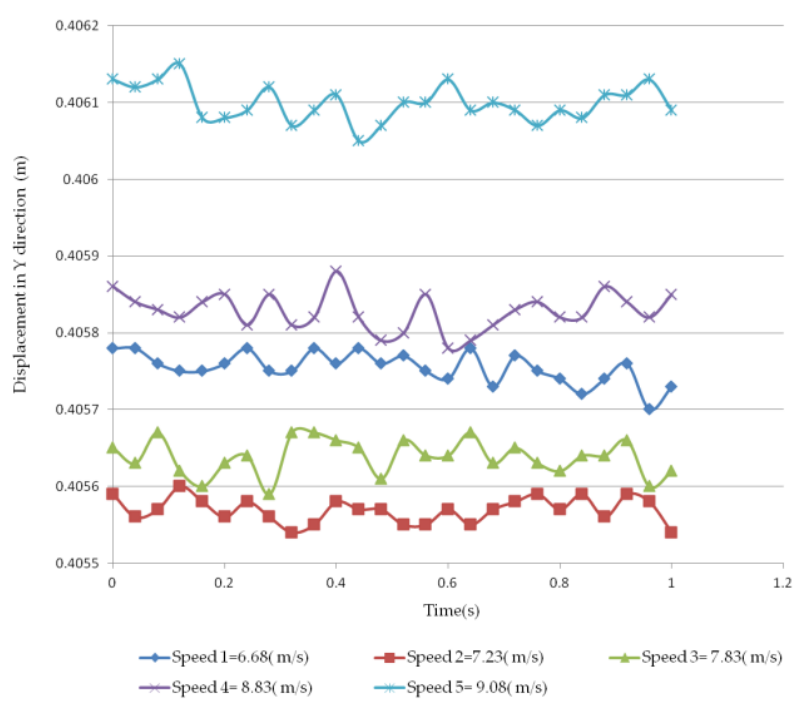

Fig. 16. Displacement response under wind load in vertical direction

\section{CONCLUSION \& RECOMMENDATIONS}

\section{A. Conclusion}

To solve the problem of electricity shortage in Sudan wind turbines could be used taking into account the presence of expansive clay and the un-saturated condition of the soil. Wind turbine structures are inherently dynamic. Loading from aerodynamic, rotational and inertia sources all contribute to a system dominated by high overturning moments and vertical loads. Turbine control mechanisms also significantly affect the dynamic response of the foundation leading to the necessity of considering dynamic soil response and soil-structure interaction in design. This paper presented a review of the type of wind turbine foundations, wind-Structure interaction, and dynamic response of wind turbine due to wind flow.

Experimental study on a scaled model wind turbine to measure the lateral displacement of a wind turbine tower under various dynamic wind loads applied was evaluated in this study. The tower exhibited a dynamic behavior where lateral displacements were captured in the main wind and vertical directions.

\section{B. Recommendations for Future Research}

Some recommendations are drawn to facilitate the way for future research:

- Finite element methods could be used to obtain dynamic response of wind turbine and natural frequencies.

- Make quick, simple and reliable approach to understand the pile dynamic behavior in expansive soil.

- Static analysis and design procedures should be used as a guideline tool for the design of piles in expansive soils.

- Structural performance and costing of this design should be investigated for local conditions.

- More tests on wind tunnel could be carried to investigate different types of foundations.

\section{ACKNOWLEDGMENT}

The first author thankful towards Dr. Amged O. Abdelatif for his guidance and support throughout the course of this research. The authors would like to thank Eng. Mutaz Omer for his helping in modeling the motion of wind turbine into PhotoModeler program that he provided is greatly appreciated.

\section{REFERENCES}

[1] Ministry of Water Resources Irrigation and Electricity, "Preparation of Sudan Wind Atlas," Khartoum-Sudan, 2018.

[2] A. D. Mukasa, E. Mutambatsere, Y. Arvanitis, and T. Triki, "Development of Wind Energy in Africa," Dev. Res. Dep. African Dev. Bank, vol. No 170, no. March 2013, pp. 1-43, 2013.

[3] Reve, "Wind energy in Africa I REVE." [Online]. Available: https://www.evwind.es/2013/05/02/wind-energy-in-africa-2/32 307. [Accessed: 06-Nov-2018]. 
[4] Y. A. Saied, "Renewable Energy Current Projects and Future Plans," in 9th German-African Energy Forum, Hamburg, May 4th-5th, 2015, 2012, pp. 1-21.

[5] W. A. Charlie, "Construction on Expansive Soils in Sudan," J. Constr. Eng. Manag., vol. 110, no. 3, pp. 359-374, 1985.

[6] S. Shrestha, "Design and Analysis of Design and Analysis of foundation for onshore tall wind turbines," Msc Research Thesis, Civil.Eng. Dept, Clemson University, 2015.

[7] "Monopiles Support Structures - 4C Offshore," 2013. [Online]. Available:

https://www.4coffshore.com/windfarms/monopiles-support-str uctures-aid4.html. [Accessed: 06-Nov-2018].

[8] "Gravity Based Support Structures - 4C Offshore," 2013. [Online].

Available: https://www.4coffshore.com/windfarms/gravity-based-support -structures-aid8.html. [Accessed: 06-Nov-2018].

[9] "Hitachi Zosen to Apply Suction Bucket Foundation Construction Method for Offshore Wind Farms I News Release I Hitachi Zosen Corporation," 2018. [Online]. Available: http://www.hitachizosen.co.jp/english/release/2018/02/002977. html. [Accessed: 06-Nov-2018].

[10] "Jacket or Lattice Structures - 4C Offshore," 2013. [Online]. Available:https://www.4coffshore.com/windfarms/jacket-or-lat tice-structures-aid5.html. [Accessed: 06-Nov-2018].

[11] "Rolf Günther Schiffsmakler Schiffahrts- und Transportservice GmbH \&amp; Co. KG:: archive 2013," 2013. [Online]. Available: http://www.rolf-guenther.de/en/news/archive-2013/. [Accessed: 06-Nov-2018].

[12] "Tripile Support Structures - 4C Offshore," 2013. [Online]. Available:

https://www.4coffshore.com/windfarms/tripile-support-structu res-aid6.html. [Accessed: 06-Nov-2018].

[13] Leah Scully, "Concrete Floating Turbine Economizes Wind Power," $2015 . \quad$ [Online]. Available: https://www.machinedesign.com/sustainable-engineering/conc rete-floating-turbine-economizes-wind-power. [Accessed: 08-Nov-2018].

[14] "KPB w Krośnie S.A. w restrukturyzacji: Elektrownie wiatrowe Hnatkowice-Orzechowce." [Online]. Available: http://www.kpb.com.pl/pl?portfolio,elektrownie_wiatrowe_hn atkowiceorzechowce. [Accessed: 08-Nov-2018].

[15] F. Miceli, "Anchor cage foundations I Wind Energy Impacts and Issues," 2014. [Online]. Available: https://www.wind-watch.org/documents/anchor-cage-foundati ons/. [Accessed: 06-Nov-2018].

[16] E. Shelton L. Stringer, PE, GE, PG, "Engineering Design and Analysis of the Patrick and Henderson Rock Anchor Foundation," 2007.

[17] Francesco Miceli, "Precast Foundations I Wind Farms Construction," 2013. [Online]. Available: http://www.windfarmbop.com/tag/precast-foundations/. [Accessed: 07-Nov-2018].

[18] "Number and Spacing of Piles in a Group. I Builder's Engineer." [Online]. Available: http://www.abuildersengineer.com/2012/11/number-and-spaci ng-of-piles-in-group.html. [Accessed: 07-Nov-2018].

[19] "India Property Realestate Builders BHK Flat Apartments Land Projects India." [Online]. Available: http://www.propertykwik.com/construction-foundations.php. [Accessed: 07-Nov-2018].

[20] "External and interaction forces that act upon a piled raft [34] I Download Scientific Diagram." [Online]. Available: https://www.researchgate.net/Fig./External-and-interaction-for ces-that-act-upon-a-piled-raft-34_fig1_265560224. [Accessed: 07-Nov-2018].

[21] International Electrotechnical Commission (IEC). 2005. IEC 61400-1 Wind turbines Part 1 - Desgin requirements. Rev. 3rd. Geneva: International Electrotechnical Commission.
[22] Det Norske Veritas (DNV) \& Risø National Laboratory. 2002. Guidelines for design of wind turbines. Rev. 2nd ed. Copenhagen: Det Norske Veritas.

[23] K. Folster and K. Hewitt, "Influence of Geometry on the Dynamic Behaviour of Steel Tubular Towers for Onshore Wind Turbines," Msc Research Thesis, Civil.Eng.Dept, University of Cape Town, 2016.

[24] W. S. van Zyl and G. P. A. G. van Zijl, "Dynamic behaviour of normally reinforced concrete wind turbine support structures," J. South African Inst. Civ. Eng., vol. 57, no. 4, pp. 38-44, 2015.

[25] A. C. Way and G. P. A. G. van Zijl, "A study on the design and material costs of tall wind turbine towers in South Africa," J. South African Inst. Civ. Eng., vol. 57, no. 4, pp. 45-54, 2015.

[26] M. O. L. Hansen, Aerodynamics of Wind Turbines, 2nd ed. London: published by Earthscan in the UK and USA, 2008.

[27] C. Van der Woude and D. S. Narasimhan, "Dynamic Structural Modelling of Wind Turbines Using COMSOL Multiphysics," in COMSOL Conference 2010, 2010, pp. 1-38.

[28] Zingoni, A, 2015. Vibration Analysis and Structural Dynamics for Civil Engineers: Essentials and Group-Theoretic Formulations. Boca Raton, Florida: CRC Press Taylor \& Francis Group.

[29] J. van der Tempel and D.-P. Molenaar, "Wind Turbine Structural Dynamics - A Review of the Principles for Modern Power Generation,Onshore and Offshore," Wind Eng., vol. 26, no. 4, pp. 1-12, 2002.

[30] Y. Liu, S. K. Vanapalli, and A. W. BA, "Load - deformation Analysis of a Pile in Expansive Soil upon Infiltration," in Proceedings of the 2nd World Congress on Civil, Structural, and Environmental Engineering (CSEE'17), 2017, pp. 1-9.

[31] Q. Q. Zhang, and Z. M. Zhang, "A simplified nonlinear approach for single pile settlement analysis, " Canadian Geotechnical Journal, vol. 49, pp. 1256-1266, 2012.

[32] O. Kiyomiya, T. Rikiji, and P. H. a J. M. Van Gelder, “Dynamic Response Analysis of Onshore Wind Energy Power Units during Earthquakes and Wind," Proc. Twelfth Int. Offshore Polar Eng. Conf., vol. 3, pp. 520-526.

\section{AUTHORS}

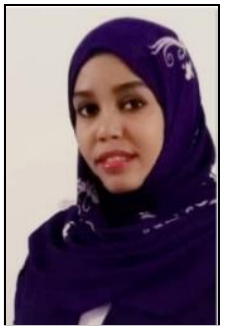

RUBA ASIM HAMZA awarded BSc degree in Civil Engineering in 2013 at Sudan University of Science and Technology, and, MSc in Structural Engineering in 2019 at University of Khartoum. She has worked as Civil engineer at Dar Consult and Sudan Pile for Roads \& Bridges.

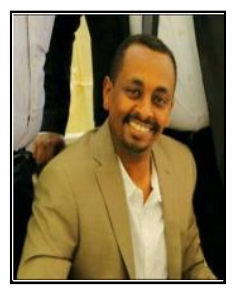

DR. AMGED OSMAN ABDELATIF has been working as an Associate Professor at the University of Khartoum, where he had his first degree in Civil Engineering (2003), and his MSc in Structural Engineering (2008). Amged completed his PhD in Civil Engineering at the University of Nottingham, UK in 2013. Also, he is the owner of www.sudacon.net for news of construction industry in Sudan (2011). 